\title{
SALVIA SUBVIOLACEA, A NEW SPECIES FROM THE HIMALAYAS-HENGDUAN MOUNTAINS, CHINA
}

\author{
Y. K. Wei ${ }^{1 *}$, C. A. Pendry², Y. B. Huang ${ }^{1}$, B. J. Ge ${ }^{1}$ \& H. W. Xiao ${ }^{1}$
}

\begin{abstract}
Salvia subviolacea Y.K.Wei \& Pendry, a new species from China, is described. Salvia subviolacea belongs to Salvia subg. Glutinaria (Raf.) G.X.Hu, C.L.Xiang \& B.T.Drew, sect. Eurysphace E.Peter, and is distinguished from morphologically similar species by differences in its habit, leaves, inflorescences and flowers. It has a disjunct distribution in Sichuan and Xizang, and its IUCN Red List conservation assessment is Endangered. The Xizang population is under extreme threat and rapid conservation measures need to be taken.
\end{abstract}

Keywords. China, new species, Salvia subviolacea, Salvia.

Received 28 October 2019 Accepted 13 July 2020 Published 09 March 2021

\section{Introduction}

The Hengduan Mountains are the easternmost extension of the Himalayas and are located in the Sichuan, Xizang and Yunnan Provinces of China. More than half of China's 83 species of Salvia L. are found in these provinces, and 23 species are endemic to the Hengduan Mountains (Wei et al., 2015). The diversity of this region has still not been fully explored, and further investigations are much needed (Li \& Hedge, 1994; Wei et al., 2015), because new species of Salvia are still likely to be found there (Wang et al., 2016). In this paper, we describe a new species of Salvia from Sichuan and Xizang and present a key to related species. Future papers will describe and document the ongoing research programme.

In 2011 and 2014, we collected a Salvia in Sichuan and Xizang that showed similarities to Salvia dolichantha E.Peter, S. hians Royle ex Benth., S. przewalskii Maxim. and S. wardii E.Peter but proved to be different from all these species. Further investigations in the field and comparison with herbarium specimens and living plants of these species have confirmed that our collections represent a new species, which is described and illustrated below.

Two subsequent surveys of the Xizang population in 2019 and 2020 found evidence of serious disturbance at the collecting locality, and no living plants could be located. It is evident that immediate measures need to be taken to protect this species.

${ }^{1}$ Shanghai Chenshan Botanical Garden, 3888 Chenhua Road, Shanghai 201602, China.

2 Royal Botanic Garden Edinburgh, 20A Inverleith Row, Edinburgh EH3 5LR, Scotland, UK.

*Corresponding author. E-mail: ykwei@aliyun.com. 


\section{Species description}

Salvia subviolacea Y.K.Wei \& Pendry, sp. nov.

Salvia subviolacea is distinguished from $S$. dolichantha E.Peter by its smaller flower and crenate leaf margin. Salvia subviolacea differs from S. hians Royle ex Benth. in its calyx and corolla; the former has a longer, narrower, uniformly deep violet to black calyx compared with the bicoloured green and deep violet, broadly campanulate calyx of the latter; furthermore, in the former the corolla tube is adnate to the calyx, whereas in the latter it is completely free. Salvia subviolacea differs from S. przewalskii Maxim. in its denser inflorescence and calyx that is much larger in relation to its corolla. It differs from S. wardii E.Peter in its smaller habit and smaller flowers, cordate leaves, and pale blue-purple to light purple corolla, in contrast to the deep blue flowers of $S$. wardii. - Type:

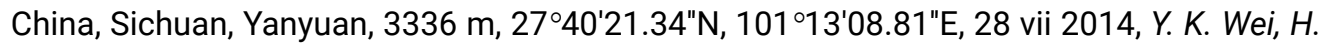
Xu \& Y.B. Huang S0617 (holotype CSH [CSH0042695]; isotype CSH, E). Figures 1, 2 A,B.

Perennial taprooted herb, 25-60 cm. Stem unbranched. Leaves almost all basal, occasionally with a pair of cauline leaves, all simple, papery, cordate to narrowly cordate, 7-20 × 5-15 cm, apex attenuate, acute or obtuse, base cordate, occasionally hastate, margin crenate. Petiole usually purplish, $5-15 \mathrm{~cm}$. Inflorescence $20-35 \mathrm{~cm}$, a relatively lax, pubescent raceme of 2- to 6-flowered verticillasters, simple or with up to 3 short branches at the base. Calyx uniformly violet or deep violet to black, tubular-campanulate, $12-21 \mathrm{~mm}$, bilabiate to half its length, upper lip rounded, without an annulus, calyx and base of corolla tube adnate. Corolla pale blue-purple to light purple, tube curving slightly upwards at base, straight, with a lanate annulus at one-third above the base, upper and lower lips concolorous or white with concolorous spots, 26-40 mm. Stamens included in the corolla, filaments 5.1-8.1 mm, connective 4.5-6.5 mm, upper arm twice as long as lower arm, upper and lower thecae fertile, lower thecae coherent. Pistil 33-43 mm, stigma included within the upper lip. Nutlets subglobose, yellow-brown, c. $2.8 \times 2.3 \mathrm{~mm}$. Indumentum of leaves puberulent or pubescent; petioles, stem, inflorescence and corolla pubescent, glandular pubescent only on the outside of the calyx.

Altitudinal range. $3000-4000 \mathrm{~m}$.

Ecology. Forest margins and understorey, roadsides. It is apparently well adapted to various habitats. Flower colour is apparently influenced by environment, with a deeper colour in drier, sunnier locations.

Phenology. Flowering June to July, fruiting July to August.

Distribution. Salvia subviolacea is endemic to China and is currently known only from the type locality at Yanyuan, Sichuan Province, and Linzhi, Xizang Province.

Conservation status. Salvia subviolacea has been observed at only two sites, which are 


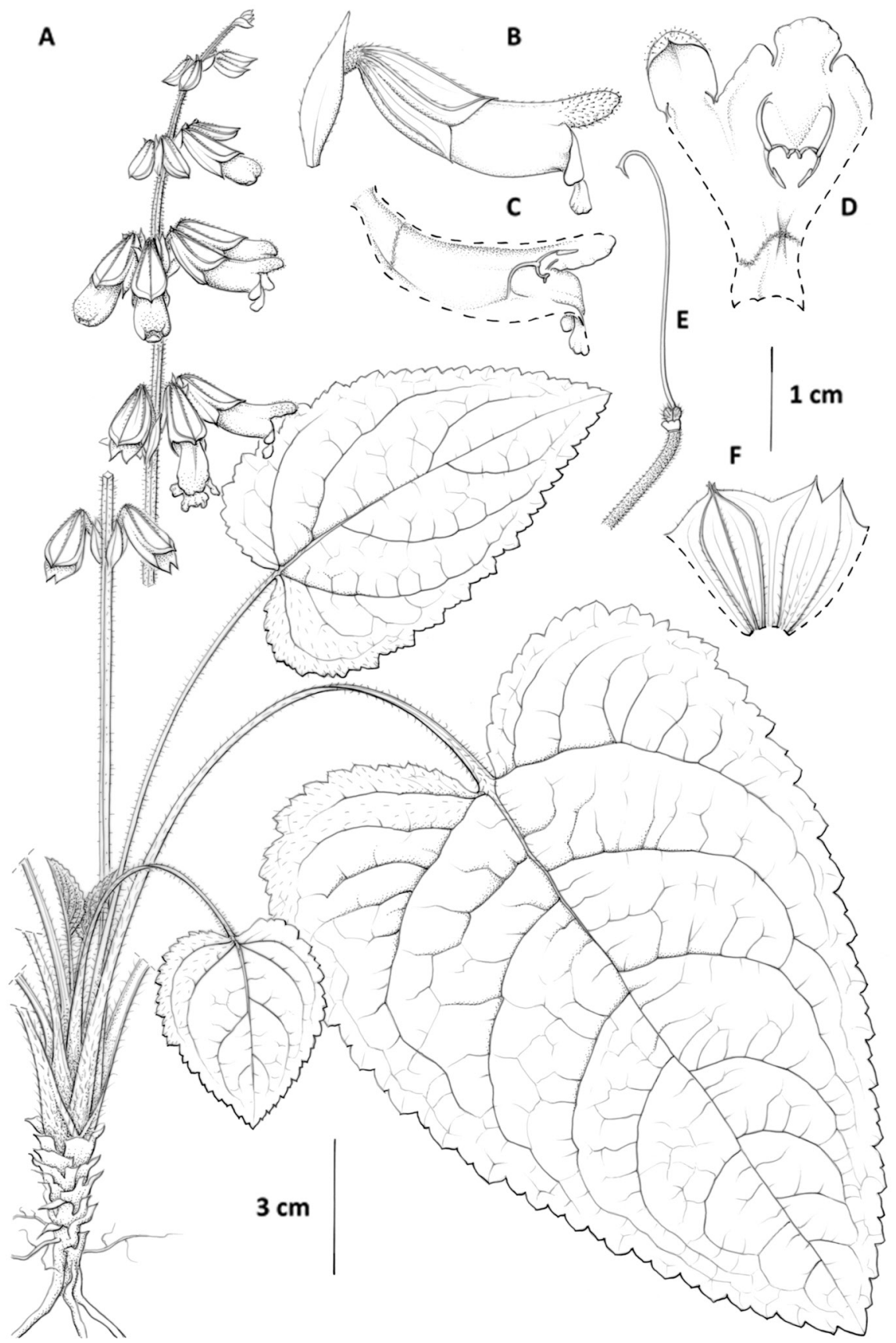

Figure 1. Salvia subviolacea sp. nov. A, Habit; B, flower (side view); C, flower (longitudinal section); $D$, corolla with stamens reflexed; $E$, ovary and style; F, dissected calyx (outer view). Scale bars: $A, 3 \mathrm{~cm}$; B-F, $1 \mathrm{~cm}$. Drawn by Claire Banks from Y. K. Wei, H. Xu \& Y. B. Huang S0617 (E). 


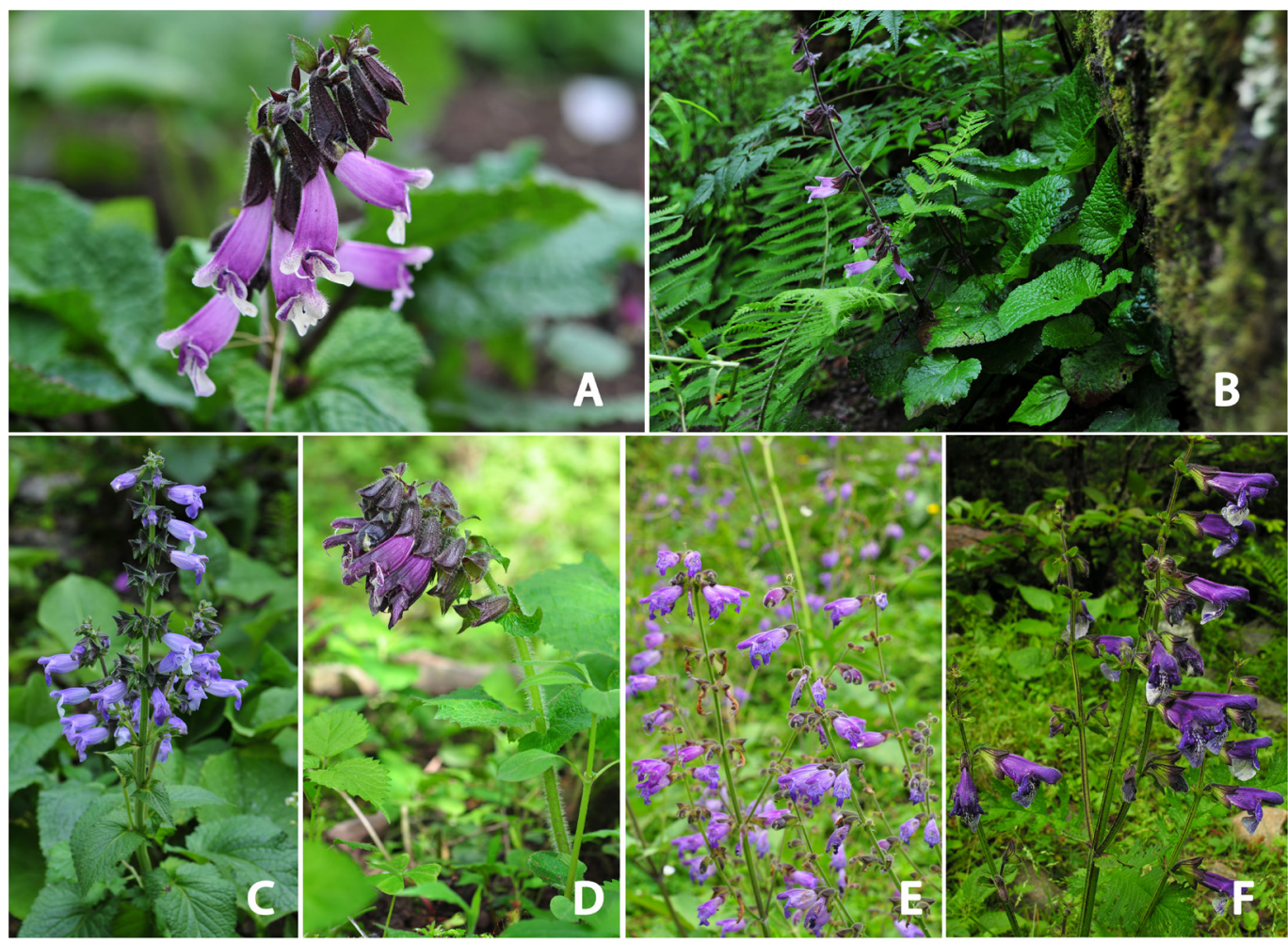

Figure 2. Salvia subviolacea and morphologically similar species: A and B, S. subviolacea; C, S. wardii; D, S. dolichantha; E, S. przewalskii; and F, S. hians.

about $360 \mathrm{~km}$ apart, among 403 localities surveyed for Salvia across Sichuan (83), Xizang (49) and Yunnan (271). Whereas the Sichuan population appears for now to be relatively steady, with between 250 and 2500 mature individuals, the Xizang population is under extreme threat. In 2019 this location was revisited but no living plants were found. The conservation assessment is therefore EN B2ac(iii) or C2b (IUCN Standards and Petitions Subcommittee, 2017).

Etymology. The epithet refers to the pale violet colour of the corolla.

Vernacular name. 川藏鼠尾草 ('Chuanzang sage').

Additional specimens examined. Sichuan: Yanyuan, Pass of Mianbu, 3240 m, 30 vii 2011, E. D. Liu, C. L. Xiang, W. Fang, W. Z. Ma, G. X. Hu, Z. H. Wang \& X. Nong 2994 (PE, KUN [two duplicates]). Xizang: Linzhi, 3937 m, 29³4'11.75"N, 94³4'31.82"E, 16 vii 2011, Y. K. Wei, B.J. Ge, L.J. Cui \& G. Xu S0239 (CSH [five duplicates]); Linzhi, Demula, 3900 m, 12 vii 2012, C. Wang LZ067 (BNU [one duplicate]). 
Similarities and differences between these species are summarised in the Table, and their comparative morphology is shown in Figure 2.

Living material was collected but the plants have not survived at Shanghai Chenshan Botanical Garden. We will attempt to set up ex situ collections at the Kunming Institute of Botany, Yunnan.

\section{Discussion}

Wu \& Li (1977) placed the Chinese species of Salvia in three subgenera (i.e. subg. Allagospadonopsis, subg. Salvia and subg. Sclarea) based on stamen structure and whether their lower arms are fertile and united. However, this classification has some obvious discrepancies, such as Salvia nipponica Miq. being placed in subg. Salvia despite its sterile lower arms, which place it in subg. Sclarea. Similarly, Salvia substolonifera E.Peter was incorrectly placed in subg. Allagospadonopisis when it actually belongs to subg. Salvia because of its fertile lower arms. A comprehensive re-examination of the Chinese Salvia was clearly much needed, with a particular emphasis on flowers from living plants.

Hu et al. (2018) established a new subgenus, Glutinaria (Raf.) G.X.Hu, C.L.Xiang \& B.T.Drew, based on molecular evidence, and treated eight major subclades within it as sections. Section Eurysphace, with 45 species, is the largest of these sections and the vast majority of its species have a Sino-Himalayan distribution and are found at high elevations. These species were divided into two subsections: subsect. Annuae and subsect. Perennes. Subsection Annuae comprises three annual or biennial species (Salvia roborowskii Maxim., S. tricuspis Franch. and S. umbratica Hance), and subsect. Perennes includes 42 species (Hu et al., 2018).

The species of subsect. Perennes can be divided into two groups - short connective and long connective - based on the relative ratio of connective to filament. In the shortconnective group, the connective is obviously shorter than the filament, whereas in the long-connective group the connective equals or is longer than the filament. Within the shortconnective group, there is a clear distinction between the species with smaller corollas (never exceeding $3 \mathrm{~cm}$; mean, $2.5 \mathrm{~cm}$ ) and of small stature (height less than $30 \mathrm{~cm}$ ) and larger plants with corollas that exceed $3 \mathrm{~cm}$ (mean, almost $4 \mathrm{~cm}$ ).

The group of small-flowered species includes Salvia brachyloma E.Peter, S. brevilabra Franch., S. evansiana Hand.-Mazz., S. lankongensis C.Y.Wu, S. mairei H.Lév., S. schizochila E.Peter and S. wuana C.L.Xiang. Salvia subviolacea belongs to the group with the larger flowers, which consists of almost 20 species including S. dolichantha, S. przewalskii and S. wardii. A key to this group is presented here. 


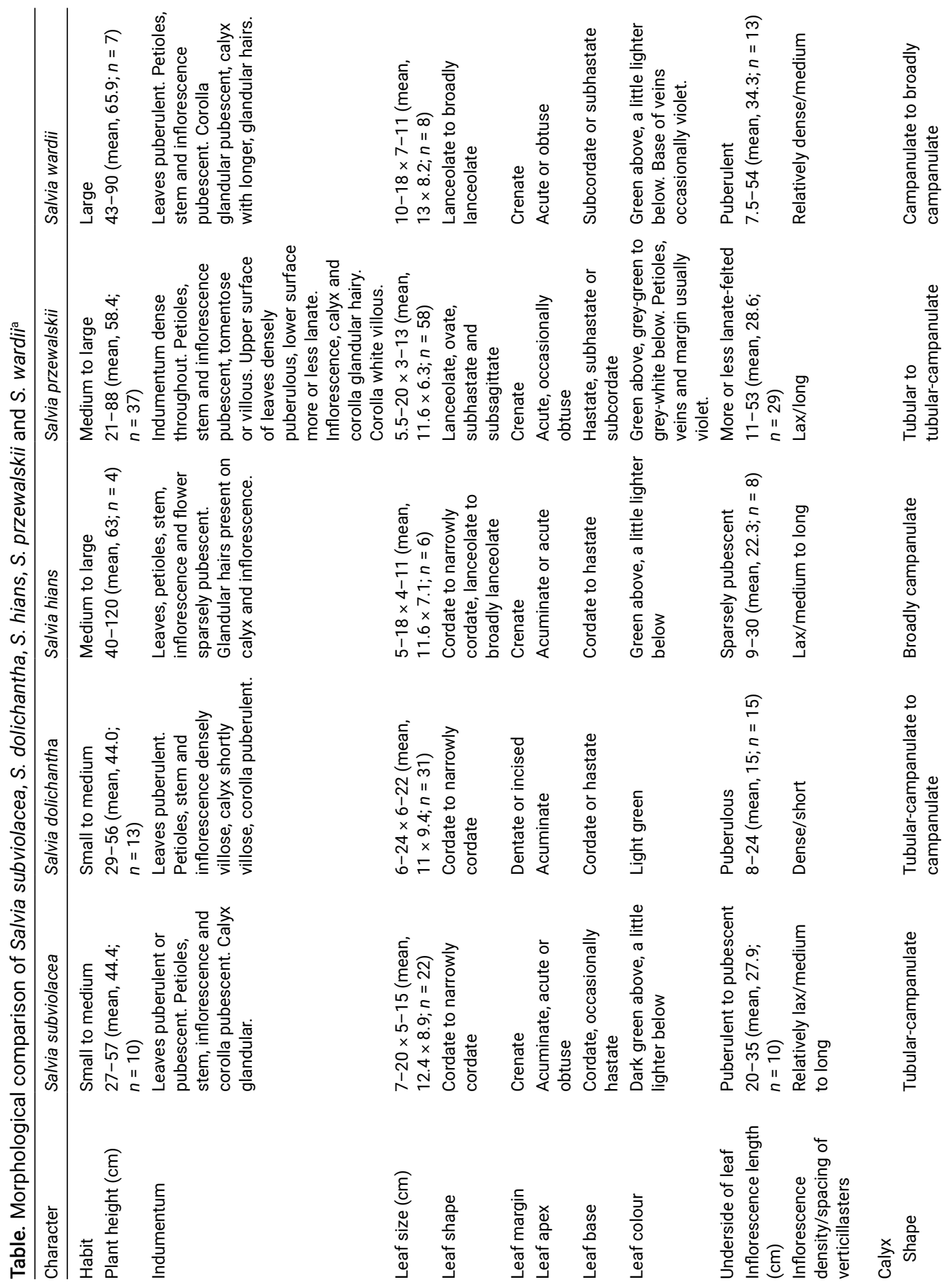




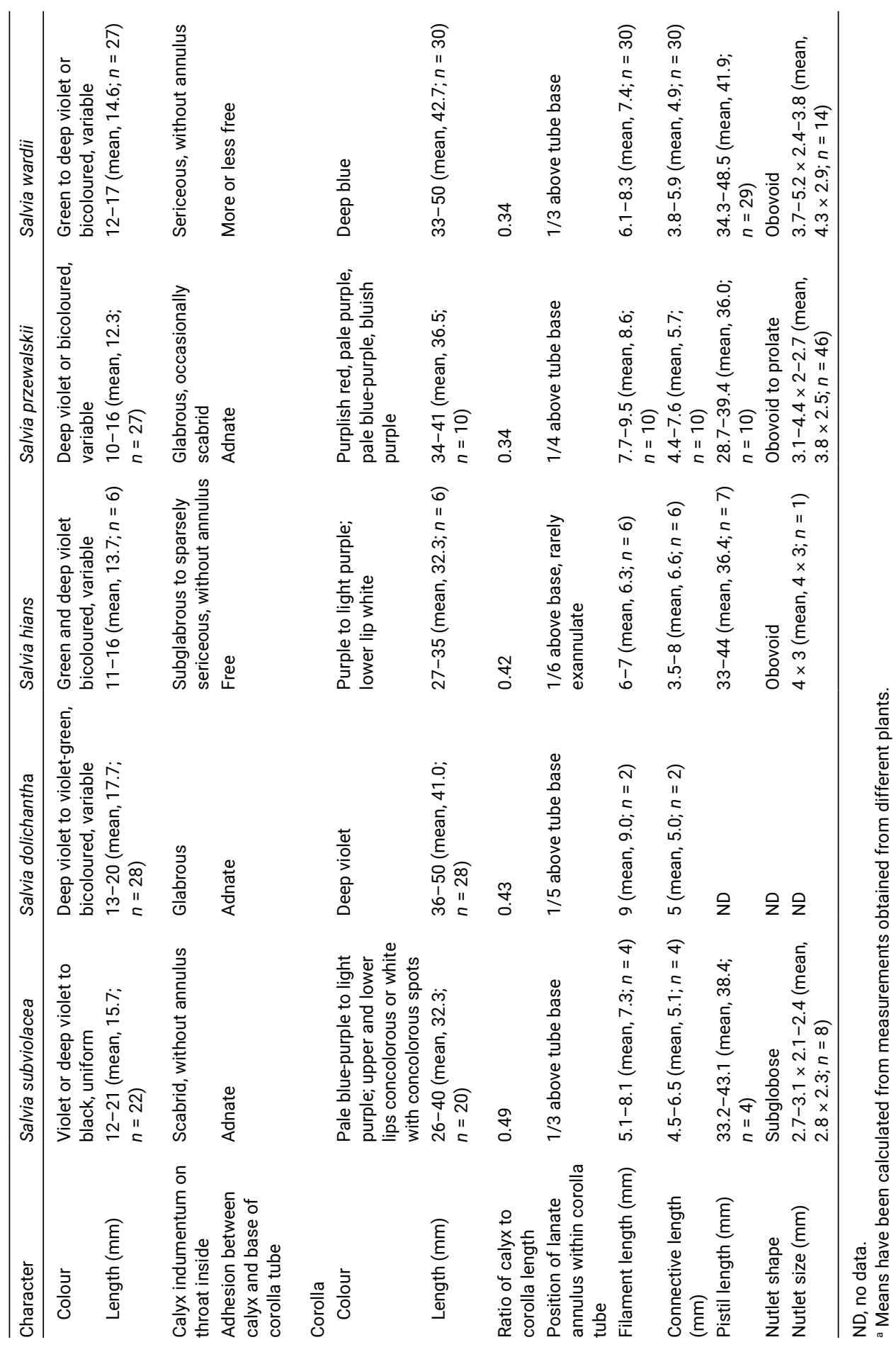




\section{Key to the Chinese species of the short-connective and big-flower group of Salvia subsect. Perennes}

1a. Corolla straight or curving slightly upwards, tube almost equally wide at middle and mouth

1b. Corolla curving upwards, sometimes somewhat S-shaped, much wider at mouth than in the middle 9

2a. Connective less than $1 / 2$ the length of the filament 3

$2 b$. Connective more than $1 / 2$ the length of the filament 4

3a. Corolla blue S. prattii Hemsl.

3b. Corolla white to cream S. potaninii Krylov

4a. Corolla length shorter than $3 \mathrm{~cm}$ 5

4b. Corolla length longer than $3 \mathrm{~cm}$ 6

5a. Leaves ovate with cordate base, pubescent above. Corolla curving slightly upwards, blue to white S. himmelbaurii E.Peter

5b. Leaves circular-cordate to ovate-cordate, villous above. Corolla straight, purple to pale purple S. paohsingensis C.Y.Wu

6a. Calyx campanulate. Corolla blue S. wardii

6b. Calyx tubular-campanulate. Corolla yellow or deep purple to light purple 7

7a. Corolla yellow. Leaf orbicular S. maximowicziana Hemsl.

7b. Corolla blue to purple. Leaf cordate to narrowly cordate 8

8a. Inflorescence dense with short internodes, densely villose. Corolla deep purple

S. dolichantha

8b. Inflorescence relatively lax, pubescent. Corolla pale blue-purple to light purple

S. subviolacea

9a. Plant $20-30 \mathrm{~cm}$ tall and usually unbranched. Corolla curving upwards 10

9b. Plant $30-60 \mathrm{~cm}$ tall, branched. Corolla curving upwards, somewhat S-shaped 11

10a. Leaf elliptic. Corolla pale purple or pink S. aerea H.Lév.

10b. Leaf ovate. Corolla white to pale yellow S. cyclostegia E.Peter

11a. Leaf tomentose 12

11b. Leaf sparsely pubescent 13

12a. Corolla pale yellow. Leaf oblong S. digitaloides Diels

12b. Corolla purple, pale purple or purplish red. Leaf broadly lanceolate, hastate or ovate

S. przewalskii 
13a. Cauline leaves present S. atrorubra C.Y.Wu

13b. Leaves all basal 14

14a. Bracts prominent, orbicular. Inflorescence compacted, usually green

S. kiaometiensis H.Lév.

14b. Bracts small, lanceolate. Inflorescence lax, usually purple S. castanea Diels.

\section{Acknowledgements}

This work was supported by Specific Project for Strategic Biological Resources and Technology Supporting System from the Chinese Academy of Sciences (grant no. ZSZY-001) and Chenshan Special Foundations from Shanghai Municipal Administration of Forestation and City Appearances (grant nos. G172410 and G182409).

The Royal Botanic Garden Edinburgh is supported by the Scottish Government's Rural and Environment Science and Analytical Services Division. We are also grateful for the support of players of People's Postcode Lottery towards our scientific research.

We wish to thank Claire Banks for her excellent illustration, and the editors and reviewers for their helpful comments.

\section{References}

Hu GX, Takano A, Drew BT, Liu ED, Soltis DE, Soltis PS, Peng H, Xiang CL. 2018. Phylogeny and staminal evolution of Salvia (Lamiaceae, Nepetoideae) in East Asia. Annals of Botany. 122(4):649-668.

IUCN Standards and Petitions Subcommittee. 2017. Guidelines for Using the IUCN Red List Categories and Criteria, version 13. http://www.iucnredlist.org/documents/RedListGuidelines.pdf

Li HW, Hedge IC. 1994. Salvia. In: Wu ZY, Raven PH, Hong DY, editors. Flora of China, Volume 17 (Verbenaceae through Solanaceae). Beijing: Science Press, and St Louis: Missouri Botanical Garden Press. pp. 196-224.

Wang T, Wang L, Zhang L. 2016. Salvia lagochia sp. nov. (Lamiaceae) from Yunnan, China. Nordic Journal of Botany. 34(1):43-47.

Wei YK, Wang Q, Huang YB. 2015. Species diversity and distribution of Salvia (Lamiaceae). Biodiversity Science. 23(1):3-10.

Wu CY, Li HW, editors. 1977. Lamiaceae. Florae Republicae Popularis Sinicae, Volume 66. Beijing: Science Press. pp. 1-647. [In Chinese, with scientific nomenclature.] 